\title{
LIVED EXPERIENCE OF INFERTILITY AMONG COMMUNITY DWELLING INFERTILE WOMEN
}

\author{
Bishnu Bista (Thapa)
}

\begin{abstract}
Objective: The aim of this study was to investigate the lived experiences of infertility among infertile women in Jhapa.

Methods: A descriptive phenomenological research design was utilized that is supported by philosophy of Edmund Husserl. Seven informants, who were having infertility problems selected for in-depth interviews, utilized purposive sampling technique. Information gathered from two Focused Group Discussions that included 20 participants and five key informants' interviews were conducted to triangulate data source which obtained from study informants. Data were recorded and transcribed verbatim later. Transcribes were deducted to extract actual meanings through coding, categorizing and organized into theme clusters.
\end{abstract}

Results: Informants experienced any one or all form of abuse like physical, emotional, psychological, societal or marital. Severity of torture depend on who had fertility related problems and infertile woman's position in husband's house. They believed their infertility problems are deeply rooted with social and cultural stigma of the society. Women, who were young and less than 15years of marriage duration, had more hope to become mother. Due to economic hardship and limited family support, they could not access to utilize Assisted Reproductive technologies.

Conclusion: though the up lift of education, media and local non-governmental organizations support and changing concepts of society, infertile women experienced risk of being isolated in social activities, threaten to divorce and remarry by husband. Accepting the realities, supporting and understanding of each other's' limitations are core factor of husband wife relationship.

Keywords: Gender, Infertile Women, Lived experience, Marital disturbances

\section{Introduction}

Infertility is one of the neglected public health problems around the world. $\mathrm{WHO}^{1}$ estimated the number of infertile couple between 8 to $12 \%$, and one out of every ten couples; roughly 60 to 80 million men and women globally have difficulty to conceive, majority of who live in developing countries. Negative consequences of childlessness are experienced to a greater degree in developing countries when compared with western societies ${ }^{2}$. Infertility has profound medical \& social consequences that affect both men \& women in all parts of the world ${ }^{1}$. It appears obvious that the social consequences of infertility are particularly harsh for women as compared to $\mathrm{men}^{3}$. In the society where the children have a special value, infertility is often a social stigma ${ }^{4}$.

The illiterate group attributed the causes of their infertility to supernatural causes while the educated group blamed nutritional, marital and psychosexual factors for their infertility ${ }^{5}$. Ramezanzaden $^{6}$ revealed that psychological consequences of infertility is directly 
associated with duration of marital life. Depression and anxiety are most common after 4 to 6 years of infertility. Especially severe depression could be found in those who had infertility for 7 to 9 years, $40.8 \%$ infertile women had depression and $86.8 \%$ had anxiety.

Infertility can lead to severe strain in a couple's relationship, their childlessness is a major theme of their lives, children are highly desired, parenthood is culturally mandatory \& childlessness socially unacceptable ${ }^{7}$. Malpani and Malpani ${ }^{8}$ highlighted that how the Indian culture placed value on having children. They mentioned that a barren woman is considered to be cursed by god, and being punished for the sins of a prior life. Infertile couples are easy and soft target for everyone - ranging from: "friends: life is incomplete without a baby! In-laws: when will I become a grandmother? Relatives: what do they want to earn money for; they do not have any children to leave it to! Co-workers: you don't have any kids, so can you stay on a little longer to finish this job - I need to go back to take care of my children!"

In Nepal, women comprise $50.5 \%$ of total population $^{9}$ but have one of the highest incidences of son preference in the world ${ }^{10}$. Adequate studies are not availability about prevalence \& consequences of infertility. NDHS $^{11}$ also does not include any data about infertility. Survey in eight districts of Nepal found $7.4 \%$ of females having infertility problem $^{12}$. In Bajhang district, a gynaecological camp showed that $14.2 \%$ women had sub-fertility morbidity ${ }^{13}$.

In condition of second marriage, Article 11 of Nepal's 1990 constitution which guarantees that "No discrimination shall be made against any citizen in the application of general laws on the grounds of sex". The court ruled that the government is under the obligation to adopt legislation that guarantees equality between husbands and wives ${ }^{14}$. Though in realities, the infertile women live with a permanent threat to be divorces, or to continue living in a polygamous family that make her to compromise quality of lifestyle and victims of such problems. It helps to explore the impact of infertility in their life, family and society. Therefore the investigator is interested \& felt the need for this type of research.

\section{Method}

A descriptive phenomenological research design was used to explore the lived experiences of infertility among the women who had infertility related problems and how they interpret their experiences. The study was conducted in selected village Development Committees (VDC) of Jhapa district. Seven study informants were recruited through snowball sampling technique who met the inclusion criteria like infertile woman who wants to have a child but involuntarily infertile for at least four years after marriage, with actively participation in sexual life without any use of contraception. For the focus group discussion, involved both men and women who have been staying for long period in the targeted community. A key informant involved in interview was selected from their long-standing experiences that were local traditional healer, FCHV, government health personnel, social worker and from local community based organization leader.

To get a similar outline of the discussions we developed an individual interview guideline and focus group guide. The discussions were focused the perceived meaning, recognition and health seeking behavior as well as impact on physical, psychological, social, and economic and marital aspect of consequences of infertility. As needed verbal clues and probing was done to the participants to clarify 
and gain more details to understand their experiences. Interviews and FGDs were conducted in Nepali and the sessions were recorded by audio-tape. Before proceeding with data collection, administrative approval was obtained from the concerned authorities.

Two session of Focus Group Discussion held with twelve females and eight males separately. Five key informants were also involved for interviews. Obtained information used for triangulation of the data provided by study informants. The process of data analysis started along with data collection. Data was analyzed in three stages as described by Miles \& Hubermans ${ }^{15}$ which included data display, data reduction and data interpretation. The extracted statements were organized in clusters of themes. The themes were described and validated by giving the evidence of verbatim of the subjects.

\section{Results}

The results are presented into demographic profile of informants and theme clusters that describes the content of this section. Some illustrative quotations are also included in the text.

\section{Socio-Demographic Profile of Informants}

The range of age of study informants were 22-40 years and their marriage duration ranged from 6- 25 years. Most of them were from Brahmin ethnic background and believed in Hinduism. Most of their economic dependency was with their family and live in joint family. Five of seven were $1^{\text {st }}$ wife of their husband and others were $2^{\text {nd }}$ wives.

\section{Defining Infertility}

The terms used for understanding of infertility have nearly similar and acceptable in the locality \& usually used it to entitle for infertile person. The most common word for infertile women- 'Banjhi', 'Bahila', and 'Aputri' and 'Alaxini'; for males- 'Aputro' and 'Namarda'; for both (men and women)'Nisantan' \& 'Aputali' were popular.

Perceived Recognition of Infertility

Informants had different perceived experience related to their infertility. Women who were $1^{\text {st }}$ wife of their husband; they did not realize they had fertility problems for 3-4 years of their marital life. They had under pressure when their husband and in laws started to accuse them, "why do not you become pregnant? It has been too long period for marriage and living with husband, we need grandson in our home'. The most common clue for recognition of infertility problems were family history of infertility, ragging and verbal abused by others and self-doubt of failure to conceive. Women who were second wife of their husband, wished to become pregnant soon. They suspected being second wife of husband and not having children after 1-2 years of marriage which avoid them being pregnant like their step.

From FGDs, it was concluded in past, people were unknown about who had infertility and seeking for treatment. They waited eight to ten years for birth of baby, if not happened, family members solely blamed to woman rather men for causes of infertility and had done $2^{\text {nd }}$ marriage of husband. Second marriage was common and accepted in sonpreferred society even if they had only daughters. Even some of men had up to fifth marriage to prove they had power of fertility. Now, people started further checkup before to blame each other and confirm that who has the fertility problems. In average, if couples failed to conceive during three to five year's period then considered as something wrong with them.

\section{Causes of Infertility}

All informants had already done more less clinical examination so that they were nearly aware and perceived what avoid them to become pregnant. Three informants perceived they had some degree of fertility weakness 
like no life time experienced of menstruation, dyspareunia, small size or enlarged uterus, small tumor and less fluid collection in uterus, frequently having lower abdominal pain, heavy bleeding during menstruation, weakness and stress; after husbands second marriage step had child within year etc. Three out of seven perceived that being childlessness is not their weakness; it's due to fertility problems present in their husbands such as impotence, premature ejaculatory problem, less ejaculation of seminal fluid, strongly refused to visit for checkup, family history of infertility within brotherhood, heavy smoking and alcoholic habits, history of step had not conceived during long period of marital life. One informant mentioned that both of them had unexplained causes of infertility. Mrs. F disclosed that "doctor had already said both of us have some degree of infertility problems. My left fallopian tube was blocked and in husband low sperms functions and count. I believed my husband had got more fertility related problem because he has impotence, only 2-3drops of fluid ejaculate after prolong (sometimes it takes 2-3hours) physical sex. Since one to two years, his habit of smoking and alcohol was increasing which might destruct sperms production."

Findings from FGDs also supported that most common infertility problems occurs in females were due to infection of uterus, hormonal causes, physical weakness, menstrual disturbances and tube blocked. Usually causes of men infertility involve abnormalities of sperm and impotence. However the problems have been presented only in man but blame always go to women. "In our family, even small one mistake of daughter in law was pointed as a big issue but for son, they overlooked his hundred mistakes". (Female, FGD). Key Informants justifies that hiding attitude and delay seeking treatment, more women suffered from pelvic inflammatory disease, STIs, uterine problems and other infections that results cause of infertility. The traditional healer shared that "I suspect infertility in women when they complained severe pain and discomfort in lower abdomen, heavy menstrual bleeding, irregular periods, loss of interest in food habits and physical weakness and men impotence as the most frequent complained".

\section{Health Seeking Behavior}

Most of the informants visited hospitals and traditional healers wherever they came to know for infertility treatment. Despite of unbelief in traditional healer some informants visited to them for 2-3 years because of in laws and friends suggestions. Informants spent much money in traditional treatment like astrologer, sacred offering. Few of them reported that often they visited to aurvedic doctor.

Almost all informants disclosed that family and relatives were main source where to go for infertility treatment. But, in laws and husband were final decision makers to permit for infertility treatment. Some participants visited to health clinics or hospital secretly with help of friends or relatives to confirm whether they had fertility related problem or not before discussion with husband and family members.

\section{Practices of Treating Infertility Traditional Methods}

"My in laws offered the Haribangsha Saptaha Pura to get mercy of god to see grandchild", said by Mrs D. All the informants kept the fasting prayer with the name of different of god and goddess to get blessing. Most of them performed the rituals of sacrifice goat and birds (cock, pigeon) in a temple or river, drank uncooked blood of vowed animals, frequently ate uncooked rice (Axata), sacrificed cloths, metals and aluminums articles with the hope to becoming mother soon. Few informants had history of using 
prayer locket in arm, neck or waist to protect from evil eyes.

Findings from FGDs also supported the traditional treatment practices of study informants. FGDs participants summarized that traditional healers and astrologers were the first persons who advised and treated for infertility in community. One of the participants shared that (male, FGD) "I was born after my grandparents visited to worship of god in Kedar (the most famous Hindu god temple, India) for grandson".

\section{Modern Methods}

Everyone informants claimed that they visited to hospital or clinic and received some kind of treatments. They had done USG, blood test and vaginal examination. Except three informants' husband, all had done sperm analysis and only one had found normal semen analysis report. Husband of two informants refused to clinical examination and one thought that his wife had anovulatory problems so he supposed not having infertility. Most of the participants were treated by injections or oral medicine either single or both partner. One participant received IUI procedure as well. Everybody wanted to become mother but due to financial circumstances and less support from husband or in laws, they could not continue their follow up visit.

Key informants highlighted that usually clients were less interested to visit health center with complained of infertility. If anyone comes, key informants referred to them in hospital or gynecologist clinic. "In past, only women came for checkup but now, usually both couple goes to the hospital to find out who has the infertility problem"

( H.A. from health post)

\section{Coping Behaviors of Informants}

In response of how do you cope with infertility problems, three informants declared that no further hope of being expected in future. Some of them believed in "In-Vitro fertilization". They were well informed about test tube baby as a treatment of infertility, available in Siliguri (India) and Kathmandu. Although, they had strong desire to have own baby, they were helpless due to expensive treatment and poor family support system. One of the informants adapted the brother in law's daughter since 8-9 years. Similarly, one informant expressed her grief "I hit axe into my own foot by forcing husband's second marriage. My step gave a birth of baby girl last year; result my husband left me alone and lived with step and daughter. Now, I had small grocery shop from where I manage my life". Most of informants mentioned that no any definite future plan and shaving money for old age. They were planning to save money for future but they have not started yet.

\section{Consequences of Infertility Social Value of Children}

Children were mandatory in society. Most of the FGDs participants expressed that two children are sufficient. In past, people preferred many children especially son, they believed that who have many sons they were rich in society. Male FGD said one says "jaska dherai chhora ushko dherai dhan, jaska dherai gaebastu usko dherai ban". The concept of son preference is slowly changing now. People wished, they had at least one or two children whether son or daughter. Parents could not raring $\&$ caring properly if they had more than two children.

Majority of the participants expressed that children are necessary for performing rite and rituals, look after family property, send the ancestors into heaven, bridging generation, proving them completeness as a man and woman, securing strong status within family and husband, performing funeral activities. Some participants thought that being a childless is worthless life, and it is misfortune due to punishment of previous life activities. 
"Grandchildren are the golden gift of god, without seeing their face, we cannot reach to heaven after dead. I do not want to end my family identity after my death. I need son not only daughter" (Female FGD).

\section{Social Status of Infertile Women}

Participants from FGDs and Key informants reported that barren women have low status in all spheres of their personal and professional life. It depends upon who has infertility problems. If fertility weakness presented with husband family members as well as husband support her and nothing to say. But, if it has with woman, most of the time husband and in laws made the situation difficult to live her together; she had two options either lives accepting tortures and violence or leaves the husband's house. Culturally, women could not leave her husband in condition of his infertility, accept that misfortune as a part of her life, being a childless for whole life and take care of husband and his family. Husband often threats wife for next marriage even he knows he has a problem. Most of the men are willing or family force to have second marriage if they are fit for fertility. Polygamy practices are life-long traumatic and distress event for women. In past, in laws and elders had not accepted to have a cup of water from infertile women's hand.

\section{Stigmatization by Society and Family}

In the past, society solely blamed the women for infertility and neglected form house. Society would not allow her to touch anything in religious ceremonies eg temple, prayer, funeral, pregnancy and newborn related functions etc. Mrs A, Mrs D said that "People were looking for where and when to humiliate or criticize to us. By saying, I saw her in morning, the day will go worse". Mrs G ventilated that "my husband and in laws always remind me come soon home, do not talk with others in familiar way, especially men..... my son becomes childless; I need a light "chirag" for my family. If you could not give grandchild, we would bring next daughter in law.....".

In past, infertile couples most stayed in distance from their parents \& brotherhood, with getting less property, saying, why they needed more without having any children to leave it. Three informants shared that according to Hindu religion, people do not want barren couple participates their rituals functions so they avoided attending. People back bitted that seeing infertile couple's face early in the morning was bad luck for whole day.

\section{Marital Relationship}

Four informants disclosed that they had marital harmony. However, the infertile women were always afraid of risk of divorce or remarry of their husband compared with participants who were second wife of their husband. One of respondents experienced limited communication with her husband though they were two members in family. She felt herself as compromise marital relationship, due to strongly defended against remarriage of husband in past. One of the participants reported that her marital relationship almost broke up because of $2^{\text {nd }}$ marriage. He's never made any phone calls for a long period. She had been living alone. One participant reported that she suggested him for second marriage but he was against the idea of that. He convenience her that he did not need any child from other woman, let she accepted what they had and enjoyed with it. Mrs F said that "From last year, every moment, I am scared when my husband brought step. Every day I suffered from emotional violence like, he had not satisfied with me (specially sexual relationship). He forced me to watch blue films and tried to have sex like that but I refused it. We have limited talk.... He threatens me for his second marriage and become a father. He blames me 
that I am fate for him..., get lost from his house... and life.... Because of you my dream house is going to destroy. Though, both of us have some infertility problems. He spreads the rumors about he is fit and I don't have uterus so he is looking girl for remarriage. I am accepting his violence silently only to keep my parents status in society".

\section{Family Relationship}

Most of the informants who were $1^{\text {st }}$ wife reported that a family member hardly support them for further treatment and emotional support even their husband had infertility problems. In laws always expect more household chores with them. But informants, who were $2^{\text {nd }}$ wife, received sound support from husband, other family members and relatives. All were suggested them to go for treatment, against for remarriage. They did not talk about children in front of them as far as possible.

"My in laws tortured me saying we need grandchildren, "give us soon, Alaxini, you make my son childless, Bahila, go away from my son's life, due to your weakness, my son losses his status in society' said Mrs C. Few of them experienced its meaningless and worthless without husband's affection though good support from in-laws. Most of the informants expressed that "they can read the unwelcoming expression in other's eyes and face for them". All of the informants happily expressed that "we are allowed in our in laws house for every rituals and religious ceremonies. No one discriminate us from participating in any works like prayer, worshiping, preparing offering....."

\section{Self-Esteem}

All the informants worried about insecurity of future life and feeling of misfortune that god had punished them by not gifting happiness of motherhood. Some participants believed if they had at least one child, their husband loves them; marital conflicts and disharmony would not come in their marital life any more. Some felt, they had misfortune so that they had married with as a second wife and always-perceiving pressure of inferior in front of others.

\section{Gender Differences}

Expressions from individual interviews, key informants and FGDs, women and men played a different role in society. Women were more suffer compared to men even they had fertility capacity. It was because patriarchal society and influenced of Hinduism. Family accused woman as Bahila, Aputri, and barrier bridging family generation because of their husband had weaknesses. Most of the men allowed remarry if their wife had infertility problem. Women always become at risk of getting step. Woman is considered the shoes of man. Wife has no option to remarry in a case when her husband is infertile.

In some cases, husband alone went to seek for treatment. If his weakness was detected he kept secret to himself and expressed everything was good about him. Most of the family, parent decided when their children marry, with or without their interest; in practice always boys are not satisfied with the choice of parents. It is the wife, who has to suffer with the anger and humiliation of her husband. If she does not get pregnant with in three to four years, other family members and neighbors also turn violate to her. Usually economic dependency of women on their husbands makes their life more difficult. She is overloaded with household chores, accused and scolded often, threaten to leave house, faces many physical, emotional, verbal and mental tortures. Even they stay at house bearing all these traumas up to death because of cultural norms, maintaining parental status in society. 


\section{Discussion}

Most of the informants represented from Brahmin and believed in Hinduism. In this study the representation of Brahmin are higher than others, which might be attributed to a higher local population of Brahmin in allocated study area. Regarding the occupation, most of all informants involve in farming, this might be due to much of rural women in Nepal have farming occupation and involve in domestic activities. Because of low educational status and cultural influence they are less access to receive opportunity and resources and their lives is economically dependent with husband. The range of married year was various started from 6-25 years. Increasing duration of marriage, couple would have less hope for baby. Two informants were $2^{\text {nd }}$ wife of their husband so that husband and family members more supported them rather who were $1^{\text {st }}$ wife. Infertile women, who were $1^{\text {st }}$ wife, always threaten to $2^{\text {nd }}$ marriage and divorce; even one participant had had step. Similar findings reported by Sami and Allis ${ }^{16}$ that respondents had been threatened for divorce $(20 \%)$ and husband's remarry $(38 \%)$.

The most common terms used for infertile women: "Bahila", "Banjhi" and "Aputri", for infertile men: "Aputro" and "Namarda" are based on their perception of infertility, which followed by socio-cultural and traditional context. Present study highlighted that perceived causes if infertility are uterine infection, no menstruation, menstrual problems, fallopian tube blocked and hormonal disturbances aggravate female infertility. Study findings from Bardiya district $^{17}$ were also corresponded to this study finding.

In this study, four informants realized that "weak sperm" of their husband prevented them from becoming mother. They reported that any defect in sperm that cause male as infertile. Previous studies also found that causes of men infertility are defect in sperm and impotence. Previous study ${ }^{18}$ noted azoospermia (54\%) and low sperm count (21\%). Two participants mentioned their barren or no motherhood was due to their husband's defect on impotence. Berg ${ }^{19}$ also reported in the study that $(63 \%)$ of males had experienced impotence.

It is evident from the study that people's health seeking behavior corresponds to their socio-economic status and support from family background. All the women in this study used different sources of traditional treatments first then consulted to modern medicine. Similar results were found by ${ }^{5}$ that faith and traditional healers were the first treatment choice among illiterate women in Kuwait. In this study, traditional healers and astrologers are advised them instructions to get children such as doing fasting prayer, Saptaha Puran, sacrifice animals and birds, using armlets, visiting temples etc. Lidia ${ }^{17}$ claimed the similar outcomes from western part of Nepal. Similar practice had reported in Nigeria $^{20}$.

Commonly in this locality, most of infertile couples prefer to go hospital (gynecologists) after getting some traditional treatments. Different types of modern treatments used by infertile women to solve their fertility problems $^{6,21}$. Likewise, in present study found all the informants were treated infertility with some kinds of treatment therapies like medicines, IUI, either single or both partners. They preferred to visit to hospital or private clinics rather primary health care center to identify problems and to confirm who had it. Ombelet $^{2}$ also stated that infertile couples always trying to receive some kinds of modern treatment from hospitals or clinics to give a birth of child.

Only two informants visited together to seek treatment. It is evident that women seek 
treatment more than the men. In practice, usually women are seeking care alone and first if she does not conceive within 2-3 years of marital period because they feel socially insecure and in order to make her social position secure and maintain respective status within family and prove her fertility although $40 \%$ of infertility problems are associated with male infertility factors ${ }^{22,23}$.

The findings of present study revealed a great value of children in study area. Infertile women experience more negative consequences of childlessness. Community values children, as insurance of their socioeconomic secure and parenthood is culturally mandatory. Qualities of couples' marital life are depended on their parenthood. Though, infertility is reproductive health problems. Some informants experienced physical violence by their husband and in laws like slapped, kicking, punching beating and hair pulled. The women who were the family member of deep-rooted conservative family, they experienced any kind of physical violence from their husband or in laws. Lidia $^{17}$ demonstrated that in community, patriarchal behavior was still present, at first, husband started to discuss about baby and he blamed wife for this reason and often he teat her after drinking alcohol.

All of the study participants perceived and experienced of emotional distress, frustration and mental torture being a barren women; anxiety and feeling of poor, pity, aimless and no more positive reflection to life. Similar findings expressed that females perceived it as more stress and generally seem to be more affected in terms of negative life consequences $^{24,25}$. From the study of relation between anxiety, depression and duration of infertility, $40.8 \%$ women had depression, $86.8 \%$ experienced anxiety, which was progress severe form that had infertility for $7-$ 9years onwards ${ }^{6}$. Findings show that due to patriarchal system pressurizes women to produce a child, if not she will suffer in the hierarchical system of female family members. In Japan $^{26}$ infertility perceived emotional stress is high $(38.6 \%)$ compare with pregnant control group women (16.0\%).

Due to fertility problems, most of the study participants reported that dissatisfaction, disharmony and frustration in their marital and sexual life. Hirsh and Hirsh ${ }^{27}$ found that infertile couples experienced significantly less sexual satisfaction than the couples in control groups. From FGDs, participants mentioned that getting satisfaction in sexual life is a main key to lock the husband -wife in happy marital relationship is being parented soon. Being motherhood means her permanent position in her husband's life and house or to assure the no remarry by her husband anymore. Women are responsible for the bridge of generation if it breaks due to infertility; everybody has complaint against her and she is vulnerable for exploitation. Childlessness means also fear of isolation and property as insecure life in old age ${ }^{28}$.

Participants from FGDs reported that in this locality, if husband and family members abused infertile women in terms of severe physical, mental and property etc, the LNGOs and mother groups are thought to be protective. They act as a mediator and create the situation that women either overcome from this violence or get property from her husband side and live independently. Hirsch and Hirsch ${ }^{27}$ explored that social support; counseling and adoption measures have positive impact to deal with the stress of infertility. Implementation of preventive measures and social support are significant to relief infertility related stress ${ }^{6}$.

Gender based biased are practiced in response to infertility, but the ways and magnitude of suffering are different. In the patriarchal line, men have power over the family's economy 
and decision-making; so, women cannot receive good treatment as well. Men believed that they have fertility capacity. Study participants noted that, now a days, usually couple visits to hospital and find out who has fertility problems and they get treatment according to available health services based on their economic status. Serour ${ }^{29}$ found that only $51-63 \%$ of the couples could afford to pay for ARTs due to expensive and difficult in many parts of the developing world.

\section{Conclusion}

In the contemporary society, infertile women are still victimized from all spare of their personal and social life although infertility is a biomedical cause. Childlessness has a profound physical, psychosocial, economical and marital impact on infertile women. They are entitled as "Bahila" \& "Aputri". Economic hardship and less supportive family made them to seek traditional healer for first treatment approach for infertility than modern medicine. Adaptive behaviors comprise sharing with friends, sisters and accepting the reality of infertility problems and economic circumstances. Usually society believes that childless means they have nobody who will support them in their old age, who will perform their funeral and look after their property. Women' status and support from husband and in laws depend up on who has the infertility problems. Concept of remarry is gradually reducing among young generation due to education, high empower of women and support from various governmental or non-governmental organizations. Only the Educational up liftmen, women empowerment and positive changing attitude in social stigma related with infertility can make the situation better for the people concerned.

\section{References}

1. Program on Maternal and Child Health and Family Planning Division of Family Health, World Health Organization. Geneva. Infertility: A tabulation of a callable data on prevalence of primary and secondary infertility, 1991. whqlibdoc.who/int/hq/1991/HWO_MCH 91.9.

2. Ombelet W, Cooke I, Dyer $\bar{S}$, Devroey $\mathbf{P}$, Devroey P. Infertility \& medical services in developing countries. Hum Reprod Update, 2008; Nov-Dec; 14(6): 605-21.

3. Inhorn MC, Buss K. Ethnography, epidemiology and infertility in Egypt. Social science and medicine, 1994; 39[(5)]:671-686.

4. Papreen $\mathbf{N}$ et al. Living with infertility: Experiences among Urban Slum Population in Bangladesh. Reproductive Health Matters, 2005;8[no. 15, May]:,33-43.

5. Fido A. Emotional distress in infertile women in Kuwait. Int J Fertil Womens Med. 2004; Jan-Feb; 49(1); 24-8.

6. Ramezandaden $\mathbf{F}$ et al. A survey of relationship between anxiety, depression and duration of infertility. BMC Women Health, 2004; Nov6; 4 (1): 9 .

7. Schmidt L. Social \& psychological consequences of infertility and assisted reproduction-What are the research priorities? Hum Fertil (Camb), 2009; Mar; 12(1): 14-20.

8. Malmani A, Malpani A. How to have a Baby: Overcoming Infertility, 2008. www.drmalpani.com/book/chapter38.html. Retrieved on 16th June 2010.

9. His Majesty's the government national planning commission central bureau of statistics Kathmandu, Nepal in figures 2001.

10. Nepal Human Development Report 2004: Empowerment and Poverty Reduction. United Nations Development Programme. http://www.undp.org.np Retrieved on $17^{\text {th }}$ June 2010.

11. USAID, New ERA, Ministry Of Health and Population (2007).Nepal Demographic and Health Survey (2006). Kathmandu: The Author.

12. UNFPA. Institute of Medicine, TU. Status of Reproductive health Morbidities in Nepal, 2006. UNFPA, Kathmandu Nepal.

13. Tuladhar H. An overview of Reproductive Health of Women in Bajhang District. Nepal Med Coll J, 2005, Dec; 7(2): 107-11.

14. Dubey P. Infertility is no ground for divorce, rules Nepalese Supreme Court, Kathmandu (Asia News), 31 Mar 2006; 23:04 Nepal.

15. Miles MB, Huberman M. Qualitative Data Analysis: A Sourcebook of New Methods. 2. Beverly Hills, CA: Sage Publications; 1994.

16. Sami N, Ali TS. Psychosocial consequences of secondary infertility in Karachi, J Pak Med Assoc.2006, Jan; 56(1): 19-22. 
17. Lidia B. Community perceptions of infertility in terms of interpretation, causes, health-seeking behaviour \& social consequences in Bardiya District, Nepal. Unpublished master's thesis, 2005.

18. Tao Chunfang, Xiao Yang. Research on women's Reproductive Health in China, 1995; New World Press.

19. Berg BJ, Wilson JF. Psychological Functioning Across Stages of Treatment for Infertile Couples. Journal of sex and marital therapy.1999; 18, 273 284.

20. Pearce T. She will not be listened to in public: perceptions among the Yoruba of infertility and childlessness in women. Reproductive Health Matters 1999; 7: 69- 79.

21. Inhorn, MC. Global infertility \& the globalization of new reproductive technologies: illustrations from Egypt. Soc. Sci Med.2003; 56(9): 1837-51.

22. Inhorn MC. Middle Eastern masculinities in the age of new reproductive technologies: male infertility and stigma in Egypt and Lebanon. Med Anthropol Q., 2004; jun; 18 (20): 162-82. Comment in: J Urol.2005 Oct; 174 (4 pt 1): 13689.

23. Kobeissi L, Inhorn MC. Health issues in the Arab American community. Male infertility in Lebanon: a case-controlled study. Ethn Dis., summer, 2007; 17 (2 suppl 3): s3-33-s3-38.

24. Greil A L, Mc Quillan J. Help-seeking patterns among U.S. women. Journal of Reproductive and Infant Psychology, 2004; 22, 305-319

25. Robinson GE, Steward DE. The psychological Impact of Infertility and New Reproductive Technologies. Harvard Review of psychiatry, 1996; 4, 168 - 172. Sahlgrenska University Hospital. (translated from the Swedish sentence: www.Cirka $10 \%$ av alla par har problem med ofrivillig barnloshet . Retrieved on $2^{\text {nd }}$ Aug. 2010.

26. Matsubayashi H, Hosaka T, Izumis, Suzuki T, Makino. Emotional distress of infertile women in Japan. Human Reprod. 2001 May; 16 (5): 966-9.

27. Hirsch AM, Hirsch SM. Long-term psychosocial effects of infertility. J Obstet Gynecol Neonatal Nurs, 1995; Jul-Aug, 24 (6): 517-22.

28. Savelsberg PF. Pludered kitchens, Empty wombs. Threatened Reproduction and Identity in the Cameroon Grassfields. The University Michigan press, 1999; 99-135.

29. Serour GI, Ghar EIM, Mansour RT. Infertility: a health problem in the Muslim world, Popul sci. Jan; 1991; 10: 41-58.

Correspondence Address: Bishnu Bista (Thapa) Department of Nursing, Nobel Medical College, Biratnagar. 